\title{
Neurobiologia das plantas: uma perspectiva interespecífica sobre o debate
}

\author{
[ Plant neurobiology: a interspecific perspective on the debate
}

\section{Guilherme Henriques Soares ${ }^{\mathrm{I}}$}

\begin{abstract}
RESUMO - Este trabalho apresenta um balanço do debate ocasionado pelas ideias suscitadas nas ciências das plantas com o advento da neurobiologia das plantas, destacando, a partir das tensões geradas entre diferentes grupos de cientistas, os elementos do que Hustak \& Myers (20I2) chamam de uma "narrativa mais rica”, além do enfoque redutivo da biologia contemporânea sobre células e genes, ou de uma lógica evolucionista neodarwiniana, e com maior atenção ao organismo e seus modos de relação. Uma narrativa que também dê conta da maneira como as plantas se expressam e permita desvelar os emaranhados nos quais plantas e cientistas estão envolvidos. Inspirada nas ideias introduzidas no campo interespecífico pelas etnografias multiespécies, a hipótese que se coloca é a de que essas tensões, sozinhas ou combinadas, sugerem modos de acessar a perspectiva das plantas. PALAVRASCHAVE - Neurobiologia das plantas; tensões;
\end{abstract}

emaranhados; perspectiva. - ABSTRACT . This paper presents a balance of the debate caused by the ideas raised in plants sciences with the advent of plants neurobiology, highlighting from the tensions generated between different groups of scientists the elements of what Hustak \& Myers (20I2) call a "richer narrative", beyond reductive focus of contemporary biology on cells and genes, or a neodarwinian evolutionary logic, and with greater attention to the organism and modes of relation. A narrative that also accounts for the way plants express themselves and reveal the entanglements in which plants and scientists are involved. Inspired by the ideas introduced in the interspecific field by the multispecies ethnography, the hypothesis is that these tensions, alone or in combination, suggest ways of accessing the perspective of the plants. - KEYWORDS · Plants neurobiology; tensions; entanglements; perspective.

Recebido em I4 de novembro de 2017

Aprovado em 27 de janeiro de 2018

SOARES, Guilherme Henriques. Neurobiologia das plantas: uma perspectiva interespecífica sobre o debate. Revista do Instituto de Estudos Brasileiros, Brasil, n. 69, p. 226-249, abr. 2018.

DOI: HTTP://DX.DOI.ORG/10.11606/ISSN.2316-901X.v0I69P226-249

I Universidade Federal do Amazonas (UFAM, Manaus, AM, Brasil). 
Há alguns anos, um grupo internacional de pesquisadores de diferentes áreas das ciências das plantas lançou uma espécie de artigo-manifesto no qual apresentavam a seguinte proposta: um novo campo de pesquisa em biologia das plantas, que busca entender como esses organismos percebem as circunstâncias e respondem aos estímulos do ambiente de maneira integrada, levando em consideração a combinação dos componentes moleculares, químicos e elétricos da sinalização intercelular. A neurobiologia das plantas (plant neurobiology), conforme foi denominada, tem como objetivo esclarecer, de modo interdisciplinar, como as plantas adquirem e processam informações, e de que maneira as respostas coordenadas afetam todo o corpo vegetal. De acordo com seus proponentes, o comportamento que as plantas exibem é coordenado através de todo o organismo por alguma forma de sinalização, comunicação e sistema de resposta integrados. Esse sistema inclui sinais elétricos de longa distância, transporte de auxinas ${ }^{2}$ mediado pela vesícula em tecidos vasculares especializados e produção de substâncias químicas conhecidas por suas características neuronais em animais?

Sobretudo, os proponentes da neurobiologia das plantas - NBP destacam que avanços recentes nas ciências das plantas claramente revelam que elas são organismos inteligentes, capazes de aprender e de tomar decisões em relação às situações enfrentadas no ambiente 4 . De acordo com essa perspectiva, e diferente do que pesquisadores mais ortodoxos acreditam, as plantas não são vítimas passivas das circunstâncias, mas antes organismos ativos no ambiente, com uma ampla gama de comportamentos, que incluem, para citar alguns deles, um sofisticado

2 Hormônios que conduzem o alongamento celular diferencial e funcionam como reguladores do crescimento em plantas.

3 BRENNER, Eric et al. Plant neurobiology: an integrated view of plant signaling. Trends in Plant Science, v. II, n. 8, p. 4I3-4I9, 2006. http://dx.doi.org/Io.IOI6/j.tplants.2006.06.009. Acetilcolina, catecolaminas, histaminas, serotonina, dopamina, melatonina, GABA e glutamato são os neurotransmissores metabólicos mais comuns nos sistemas nervosos dos animais, cumprindo papéis nas sensações, locomoção, visão, processamento de informações e desenvolvimento. Cada um desses compostos está presente nas plantas, frequentemente em concentrações relativamente altas.

4 TREWAVAS, Anthony. Aspects of plant intelligence. Annals of Botany, v. 92, n. I, 2003, p. I-20. http://dx.doi. org/Io.I093/aob/mcgIoI. Todas as traduções das citações são minhas. 
idioma químico (via emissão de compostos voláteis) para a comunicação intra e interespecífica, a capacidade de memorizar experiências estressantes no ambiente e resgatar essa informação para tomar decisões a respeito de suas atividades futuras, e o reconhecimento de raízes pertencentes ao próprio sistema e a sistemas estranhos.

Os proponentes da NBP identificam ainda estruturas ao nível celular e dos tecidos com funções análogas às dos componentes de um sistema nervoso, como sinapses vegetais, que consistem em domínios adesivos estáveis suportados por actina ${ }^{6}$, reunidos nas paredes celulares entre células adjacentes de uma mesma fileira; os ápices das raízes funcionariam como centros de comando semelhantes a um cérebro, dada a intensa atividade elétrica e o alto grau de ordenamento das células; os tecidos vasculares, como o floema e o xilema, por sua vez, fariam o papel dos neurônios, responsáveis pela transmissão elétrica, hidráulica e molecular ao longo de todo o corpo vegetal7. Essas estruturas formariam um sistema integrado de comunicação ao longo de todo o corpo vegetal.

A proposta suscitou a reação inflamada de botânicos renomados de vários países ${ }^{8}$, indignados principalmente com a livre transposição do termo "neurobiologia" (o que implica a presença de um sistema nervoso, um privilégio dos animais), o uso descabido de metáforas e analogias, e a atribuição às plantas de faculdades como inteligência, escolha, memória e aprendizado, o que representa, para muitos críticos, cometer um dos maiores pecados nas ciências naturais: antropomorfismo, ou seja, atribuir características entendidas comumente como humanas aos demais organismos. Na medida em que os detalhes do sistema de sinalização, comunicação e resposta integrados nas plantas ainda não estão totalmente esclarecidos para os dois lados, sublinho o debate sobre o alegado comportamento inteligente das plantas.

\section{Caminhando NO FiO da NAVALHa}

Em um artigo seminal, um dos mais eloquentes defensores da inteligência das plantas, Anthony Trewavas, definiu inteligência como "crescimento e desenvolvimento adaptativamente variável ao longo do tempo de vida de um

5 Pesquisas recentes mostram que as árvores são capazes de trocar informações também através da micorriza, uma associação simbiótica entre as raízes, o micélio de certos fungos e bactérias. Ver: BABIKOVA, Zdenka et al. Underground signals carried through common mycelial networks warn neighbouring plants of aphid attack. Ecology Letters, v. I6, n. 7, 20I3, p. 835-843. http://dx.doi.org/Io.IIII/ele.I2II5.

6 Proteína presente nas miofibrilas citoplasmáticas - organelos tubulares dispostos em feixes longitudinais que preenchem quase totalmente o citoplasma das células musculares - e essencial para a contração muscular.

7 BALUŠKA, František et al. Neurobiological view of plants and their body plan. In: BALUŠKA, F; MANCUSO, S.; VOLKMANN, D. (Org.). Communication in plants: neuronal aspects of plant life. Germany: Springer, 2006, cap. 2, p. I9-35.

8 ALPI, Amedeo et al. Plant neurobiology: no brain, no gain?. Trends in Plant Science, v. I2, n. 4, p. I35-I36, 2007. http://dx.doi.org/Io.IoI6/j.tplants.2007.03.002. 
indivíduo". Comportamento inteligente, então, seria aspecto de um “comportamento adaptativo complexo que provê a capacidade para a resolução de problemas" ${ }^{\text {זo }}$. De modo alternativo, mas em certo sentido complementar, Brenner et al. definiram inteligência das plantas como "a habilidade intrínseca de processar informação a partir de estímulos tanto bióticos como abióticos, que permite tomar decisões ótimas acerca de atividades futuras em um dado ambiente"гі.

Para Struik et al., "resolução de problemas" e "decisão", termos-chave no debate, sugerem comportamento e aprendizado individual, portanto, variações nas capacidades de aprendizado de planta para planta e, consequentemente, de atingir condições ótimas de existência e sucesso reprodutivo (fitness). Ressaltam ainda que inteligência requer uma rede de elementos capazes de um fluxo de informação adaptativamente variável, assim como a comunicação entre esses elementos. Isso seria bastante complicado no caso das plantas, que consistem em uma rede de milhões de células organizadas em cerca de dez tecidos e numerosos meristemas que influenciam uns aos outros. Assim, mesmo reconhecendo que a complexidade da comunicação ao longo do corpo vegetal, das interações com plantas da mesma espécie e com outras espécies de plantas e animais é de fato impressionante, Struik et al. não se deixam convencer facilmente de que esses processos de sinalização são reflexos de um comportamento inteligente, questão sobre a qual, afirmam, há poucas evidências disponíveis. Ademais, lembram os autores, os termos mencionados inevitavelmente evocam a noção de consciência e vontade própria, elementos que

9 TREWAVAS, Anthony, 2003, op. cit., p. I. Trewavas baseia-se na definição de inteligência desenvolvida por: STENHOUSE, David. The evolution of intelligence - a general theory and some of its implicantions. London: George Allen and Unwin, I974.

Io TREWAVAS, Anthony, 2003, op. cit., p. I.

II BRENNER, Eric et al., 2006, op. cit., p. 4I4. 
serão totalmente desnecessários se as respostas adaptativas forem passivas, como em um mundo darwiniano ${ }^{\mathrm{I2}}$.

De maneira direta e contundente, Struik et al. afirmam que a NBP se baseia em evidências científicas limitadas e na extrapolação de analogias. De acordo com eles, as ferramentas usuais das disciplinas correntes explicam satisfatoriamente os fenômenos em questão, e acusam a NBP de ferir o princípio da parcimônia (também conhecido como a Navalha de Ockham), que recomenda, ao deparar com duas teorias sobre o mesmo fenômeno, selecionar aquela que introduza o menor número de premissas e trabalhe com o menor número de hipóteses ${ }^{13}$.

Em resposta às críticas, Brenner et al. ${ }^{\mathrm{I} / 4}$ escrevem que a NBP está, antes de mais nada, perseguindo um quadro de ideias introduzido por representantes excepcionais das ciências das plantas séculos antes, como Wilhelm Pfeffer, Charles Darwin, Julius von Sachs, Georg Haberlandt e Erwin Bünning. Esses pensadores há muito chamaram atenção para o complexo comportamento das plantas e não hesitaram em atribuir um tipo de inteligência que na época chamaram de rudimentar ${ }^{15}$. Além disso, Brenner e seus colegas dizem não estarem tão preocupados com terminologias

I2 STRUIK, Paul et al. Plant neurobiology and green plant intelligence: science, metaphors and nonsense. Journal of the Science of Foof and Agriculture, v. 88, n. 3, 2008, p. 363-370. http://dx.doi.org/ Io.I0o2/jsfa.3I3I. Para uma crítica pormenorizada da noção de inteligência em plantas, ver: FIRN, Richard. Plant intelligence: an alternative point of view. Annals of Botany, v. 93, n. 4, 2004, p. 345-35I. http://dx.doi.org/Io.Io93/aob/mcho58; e a resposta de: TREWAVAS, Anthony. Aspects of plant intelligence: an answer to Firn. Annals of Botany, v. 93, n. 4, 2004 , p. 353-357. http://dx.doi.org/Io.I093/aob/mch058. Nesse debate, vale destacar a controvérsia espinhosa a respeito da consideração da planta como um indivíduo. Struik et al. estão do lado de Firn, para quem de maneira alguma a planta pode ser considerada como tal, dados os argumentos supracitados. A noção de indivíduo defendida por Trewavas (op. cit.), no entanto, não nega a organização modular das plantas, mas antes se refere à integridade do organismo sentida através da comunicação ao longo do corpo vegetal. Apesar de que, aqui, o leitor minimamente familiarizado com o trabalho de Darwin suspeita que Struik et al. estejam se referindo, na verdade, às narrativas neodarwinianas surgidas no início do século XX, e não ao pensamento de Darwin, que se revela, após um exame mais cuidadoso de seus escritos, bem mais complexo e interessante do que o determinismo um tanto grosseiro das primeiras, como bem mostram, por exemplo, Hustak \& Myers, citadas em uma seção posterior desse artigo: HUSTAK, Carla; MYERS, Natasha. Involutionary momentum: affective ecologies and the sciences of plant/insect encounters. Differences: A Journal of Feminist Cultural Studies, v. 23, n. 5, 20I2, p. 74-п18. http://dx.doi. org/IO.I2I5/IO4O739I-I892907.

I3 STRUIK, Paul et al., op. cit., p. 368-369.

I4 BRENNER, Eric et al. Response to Alpi et al.: Plant neurobiology: the gain is more than the name. Trends in Plant Science, v. I2, n. 7, 2007, p. 285-286. http://dx.doi.org/Io.IoI6/j.tplants.2007.06.005.

I5 Aqui, os proponentes da NBP indicam que estão atentos às ideias desses “naturalistas”, que desenvolveram narrativas bem diferentes das interpretações, digamos, mais modernas delas. Duas narrativas diferentes envolvendo Darwin são, no caso em específico, acionadas na controvérsia envolvendo a NBP: de um lado a interpretação neodarwiniana do conceito de adaptação contida no argumento de Struik et al. - operando nesse momento como porta-voz dos opositores - e do outro a hipótese de Darwin e seu filho, mobilizada pelos proponentes da NBP, a respeito de um centro de comando nas pontas das raízes que agiria de maneira semelhante a um cérebro rudimentar. Sobre este último ponto, ver: BALUŠKA, František et al. The root-brain hypothesis of Charles and Francis Darwin. Plant Signaling e Behavior, v. 4, n. I2, 2009, p. II2I-II27. 
- se "neurobiologia" é ou não um termo apropriado para descrever os processos de sinalização, comunicação e resposta das plantas -, mas com certos fenômenos aos quais se tem dado pouca atenção nas pesquisas e que precisam ser encarados caso se almeje um verdadeiro entendimento das operações realizadas pelas plantas, particularmente nos dias de hoje, com novas tecnologias disponíveis. Um exemplo seriam os meios de propagação, propósito biológico e componentes moleculares envolvendo os sinais elétricos, sobre os quais se sabe pouco até então, desde a primeira constatação desse fenômeno em plantas há mais de Ioo anos ${ }^{16}$. Em suma, os autores defendem que a NBP cria um importante e ainda não preenchido nicho para a biologia das plantas e move-se em direção a uma visão mais integrada, buscando o significado da comunicação que as plantas estabelecem internamente, entre si e com outros organismos.

Os proponentes da NBP e alguns de seus fiéis colaboradores argumentam ainda que em nenhum momento afirmaram a existência de um sistema nervoso como o dos animais, muito menos a existência de algum órgão parecido com um cérebro nas plantas em um sentido dogmático. Trata-se de estabelecer certas analogias em termos de função com componentes de um sistema nervoso, em sentidos específicos para as plantas, e em contextos significativos para esses organismos, tratando de seus próprios problemas ${ }^{17}$. O parco conhecimento dos processos de sinalização e comunicação, assim como dos mecanismos integrados de respostas aos estímulos do ambiente recebidos pelas plantas, aponta para a necessidade de desenvolver novos experimentos e abordagens mais criativas, e é nesse sentido que as metáforas e interpretações que desenvolvem vêm a contribuir para o avanço das ciências das plantas, assim como para um melhor entendimento do mundo vegetal. Além do mais, chamam a atenção para o fato de que as definições usuais de inteligência, aprendizado, escolha, memória e consciência são antropocêntricas, o que nos impede de apreciar tais qualidades quando apresentadas por outros seres, daí a necessidade de expandir os significados dessas palavras, até mesmo porque não existe exatamente um consenso sobre como defini-las ${ }^{18}$.

Anthony Trewavas também responde às críticas endereçadas à NBP, ressaltando o valor das metáforas fornecidas por ela para a sinalização e biologia das plantas. Segundo o autor, o valor das metáforas reside nas questões experimentais que provocam e que poderiam não ser imediatamente óbvias em sua ausência. Em outras palavras, metáforas ajudam a estimular a imaginação investigativa dos bons cientistas. As metáforas da NBP não seriam nem exceções, nem aberrações, mas um

I6 STAHLBERG, Rainer. Historical overview on plant neurobiology. Plant Signaling e Behavior, v. I, n. I, 2006, p. 6-8.

I7 BALUŠKA, František; MANCUSO, Stefano. Plant neurobiology: from sensory biology, via plant communication, to social plant behavior. Cognitive Processing, v. Io, n. I, 2009, p. 3-7. http://dx.doi.org/Io.I007/ sI0339-008-0239-6.

I8 TREWAVAS, Anthony; BALUŠKA, František. The ubiquity of consciousness. Embo Reports, v. I2, n. I2, 20II, p. I22I-I225. http://dx.doi.org/Io.IO38/embor.20II.2I8. 
complemento essencial à mente científica imaginativa ao confrontar alguns dos mais recalcitrantes problemas em biologia das plantas ${ }^{\mathrm{I}}$.

A despeito do acirrado debate, os dois principais proponentes da NBP, Stefano Mancuso e František Baluška, seguiram utilizando o conceito nas pesquisas desenvolvidas no International Laboratory of Plant Neurobiology - LINV, dirigido por Mancuso e localizado na cidade de Florença, Itália. Em junho de 2016 foi realizada a quarta edição do International Symposium on Plant Signaling and Behavior, organizado pela associação de mesmo nome e da qual fazem parte vários dos proponentes e colaboradores da NBP. Essa associação, fundada em 2005 e inicialmente intitulada Society of Neurobiology of Plants, se viu obrigada a adotar um nome menos controverso devido a pressões do establishment científico ${ }^{20}$.

Artigos sobre sinalização, comunicação, comportamento e inteligência das plantas são publicados frequentemente nas páginas da revista Plant Signaling and Behavior, criada para esse propósito. Essa produção se inscreve, segundo Baluška e Mancuso, em um movimento relativamente recente nas ciências biológicas, que atravessa uma encruzilhada crítica, partindo de conceitos e metodologias reducionistas e mecanicistas em direção a análises pós-genômicas, holísticas e baseadas em sistemas de redes hierárquicas integrados e comunicativos, indicando uma potencial mudança de paradigma em curso. Apesar das numerosas descobertas nas décadas anteriores em consideração à estrutura das células e seus componentes, fica cada vez mais claro, segundo os autores, que as promessas mecanicistas e genocêntricas em biologia não

I9 TREWAVAS, Anthony. Response to Alpi et al.: Plant neurobiology - all metaphors have value. Trends in Plant Science, v. I2, n. 6, 2007, p. 23I-233. http://dx.doi.org/Io.IoI6/j.tplants.2007.04.006.

20 Embora eu não a aborde diretamente neste texto, talvez o principal ponto envolvendo essa controvérsia entre cientistas seja a questão do vocabulário. A discussão entre os proponentes da NBP e seus opositores parece se concentrar muito mais em torno das terminologias apropriadas para descrever o que as plantas fazem apesar de os próprios cientistas em alguns momentos afirmarem o contrário - do que propriamente sobre o que elas fazem afinal, aspecto sobre o qual parece haver uma concordância geral acerca da complexidade dos processos envolvidos e necessidade de conhecê-los melhor. Essa questão do vocabulário opera de múltiplas maneiras dentro da controvérsia, ou melhor, gera, possivelmente, diferentes controvérsias: se é prudente falar em "neurobiologia" para estudar organismos que formalmente não possuem um sistema nervoso; se o uso de metáforas e analogias, tomando emprestados termos da fisiologia animal para descrever processos e estruturas presentes nas plantas, é apropriado; ou na busca por definir o conceito de inteligência em termos não antropocêntricos, onde se apela ora a uma perspectiva universalista, inteligência como sinônimo de adaptação (fitness) - uma propriedade emergente da vida, necessária a todo ser vivo ao se relacionar com o ambiente (equiparando, nesse sentido, o conceito ao de cognição) -, ora a uma perspectiva deveras particular, que tem relação estritamente com o que as plantas fazem e como fazem, na qual o conceito de inteligência só adquire sentido se for adjetivado, no caso, inteligência das plantas. É necessário, portanto, começar separando essas controvérsias de vocabulário, mostrando que esses termos não são neutros, pelo contrário, são epistemológica e ontologicamente comprometidos. Um exercício como esse pode contribuir para o apuro conceitual ou para uma imaginação científica capaz de tornar mais claro o que une e separa esses cientistas na peleja, fazendo do pesquisador uma espécie de diplomata intelectual. 
passam de quimeras, e que os organismos viventes são muito mais complexos do que a soma dos seus constituintes ${ }^{2 \mathrm{I}}$.

Vários dos cientistas que, de uma maneira ou de outra, estão associados à NBP compartilham da ideia de que os sistemas vivos, sejam uma única célula ou organismos mais complexos, como animais e plantas, não são máquinas nem autômatos que respondem aos sinais externos através de um conjunto limitado de respostas predefinidas e reflexos automáticos. Muitos apontam que, enquanto os animais, em parte, e até mesmo as bactérias já conseguiram se livrar dessa carga e ter suas capacidades agentivas reconhecidas, ainda é comum pensar nas plantas como dispositivos mecânicos sem qualquer possibilidade de escolha e planejamento de suas atividades, conforme atesta a reação dos críticos mais conservadores às ideias da NBP. Para Baluška e Mancuso, a quantidade considerável de dados produzidos nos últimos anos demanda a reconsideração desse ponto de vista sobre as plantas ${ }^{22}$.

Em reação a essa onda de novas informações, pesquisadores de diversas áreas são atraídos pela discussão sobre a inteligência das plantas, reavivada, tal como foi, pela NBP e trazida de volta ao meio científico, mesmo com resistência. Nesse tocante, vale dizer que nem todos os críticos da NBP estão empenhados em refutar a ideia, alguns buscam contribuir com perspectivas para a construção e consolidação do campo, introduzindo abordagens oriundas de outras disciplinas ou áreas de estudo, como a filosofia, a biologia da cognição e a ecologia psicológica, por exemplo, para ponderar a relação entre as plantas e o ambiente, com todas as implicações.

\section{Da COMPUTAÇão À ATENÇão}

Os proponentes da neurobiologia das plantas, tal como vimos anteriormente, interpretam as plantas como redes de procesamento de informações, enfatizando o perfil computacional funcional que explica o comportamento inteligente manifesto desses organismos. Aspectos como comportamento competitivo, memória, aprendizado e tomadas de decisão são privilegiados no tipo de análise que desenvolvem. Outros (incluindo alguns críticos menos tenazes da NBP) também elaboraram trabalhos nessa mesma linha, enfatizando explicações funcionais e priorizando as estruturas e os componentes que possam sustentar um comportamento inteligente, assim como tentando definir com mais rigor seus pré-requisitos ${ }^{23}$. Recentemente, Trewavas publicou uma revisão atualizada do seu

$2 \mathrm{I}$ BALUŠKA, František; MANCUSO, Stefano. Plant neurobiology as a paradigm shift not only in the plant sciences. Plant Signaling o Behavior, v. 2, n. 4, 2007, p. 205-207.

22 Idem. Plant neurobiology. From stimulus perception to adaptive behaviour of plants, via integrated chemical and electrical. Plant Signaling er Behavior, v. 4, n. 6, 2009, p. 475-476.

23 Ver, por exemplo: BARLOW, Peter W. Reflections on plant neurobiology. BioSystems, v. 92, n. 2, 2008, p.I32-I47. http://dx.doi.org/Io.IoI6/j.biosystems.2008.oI.oo4; CVRCKOVÁ, Fatima; LIPAVSKÁ, Helena; ZÁRSKÝ, Viktor. Plant intelligence: why, why not or where?. Plant Signaling Behavior, v. 4, n. 5, 2009, p. 394-399; KARPIŃSKI, Stanislaw; SZECHYŃSKA-HEBDA, Magdalena. Secret life of plants: from memory to intelligence. Plant Signaling er Behavior, v. 5, n. II, 20IO, p. I39I-I394. 
trabalho de muitos anos sobre inteligência das plantas, na qual endossa muitas de suas conviç̧ões anteriores que vão ao encontro dos pressupostos da NBP ${ }^{24}$.

Como é possível perceber, esse enfoque evoca as capacidades cognitivas das plantas. Isso pode ser problemático se levarmos em consideração a crítica de Firn ${ }^{25}$ à noção da planta como um indivíduo utilizada por Trewavas ${ }^{26}$. Conforme Firn destaca, qualquer tipo de inteligência que possa ser atribuída às plantas pode residir apenas nos tecidos, órgãos ou células, já que o conceito de planta como um indivíduo é, no mínimo, enganoso, dado o seu crescimento e desenvolvimento modular ${ }^{27}$. Nesse sentido, Garzón ${ }^{28}$, membro do Conselho Científico do LINV e colaborador assíduo das pesquisas desenvolvidas no laboratório, concorda com Firn, entretanto, para ele, o conceito de indivíduo é enganoso para se referir tanto às plantas como a qualquer outro organismo. $\mathrm{O}$ autor defende que o nível do indivíduo deve ser deixado de lado em favor de um indivíduo estendido, ou um "indivíduo-acoplado-com-seu-ambiente"29, colocando em questão o indivíduo como o lócus da inteligência. Desse modo, rejeita a metáfora da cognição como um processo centralizado em favor da concepção de um fenômeno auto-organizado estendido e emergente, cuja explicação requer o entendimento simultâneo dos fatores neurais, corporais e ambientais, conforme interagem uns com os outros em tempo real.

Aqui, cognição é entendida, em um sentido amplo, como o comportamento de todo e qualquer ser vivo em relação ao seu ambiente ${ }^{30}$. Esse entendimento é inspirado em autores como Maturana \& Varela ${ }^{31}$ e Bateson ${ }^{32}$, para os quais a cognição, definida como o ato de conhecer, é implícita a todas as formas de vida, construída como tal a partir de estruturas de redes hierárquicas complexas ${ }^{33}$. Para esses autores, mesmo organismos como as plantas, sem um sistema nervoso central, percebem e respondem

24 TREWAVAS, Tony. Plant intelligence: an overview. BioScience, v. 66, n. 7, 20I6, p. 542-55I. http://dx.doi. org/I0.I093/biosci/biw048.

25 FIRN, Richard, op. cit.

26 TREWAVAS, Anthony, 2003, op. cit.

27 FIRN, Richard, op. cit., p. 346.

28 GARZÓN, Francisco Calvo. The quest for cognition in plant neurobiology. Plant Signaling e Behavior, v. 2, n. 4, 2007, p. 208-2II.

29 Ibidem, p. 209.

30 TREWAVAS, Anthony; BALUŠKA, František, op. cit., p. I22I.

3I MATURANA, Humberto; VARELA, Francisco. Autopoieses and cognition. Dordrecht: the Netherlands, I990.

32 BATESON, Gregory. Mind and nature. A necessary unity. London: Fontana, I985.

33 TREVAWAS, Anthony. A brief history of systems biology. The Plant Cell, v. I8, n. Io, 2006, p. 2420-2430. http:// dx.doi.org/IO.II05/tpc.I06.042267. 
e, por isso, conhecem seu ambiente ${ }^{34}$. Elas são, desse modo, capazes de cognição. Contudo, ao definir o ato cognitivo, Gárzon o coloca em termos de manipulação de representações, isto é, estados internos formados a partir dos sinais recebidos do ambiente, transformados e devolvidos como respostas ${ }^{35}$.

Em uma aproximação com a ecologia psicológica, no intuito de explorar de modo mais acurado o processo dinâmico de interação no sistema organismo-ambiente que caracteriza o domínio cognitivo tal como acabamos de ver, Gagliano ${ }^{36}$ investe na intrínseca relação entre percepção e habilidades cognitivas, a primeira entendida como - mais do que o processo total de recebimento, organização e interpretação de uma variedade de estímulos - a experiência de fazer contato com o mundo e explorar quais oportunidades o ambiente oferece. Para isso, baseia-se no conceito de affordance, processo de descoberta e avaliação dinâmica das múltiplas oportunidades apresentadas ao organismo, através do qual certas respostas cognitivas como predição e antecipação são facilitadas pelo ambiente, permitindo àquele conhecer acerca do estado do mundo antes de dedicir e agir nele. Nessa perspectiva, o ambiente, ao oferecer múltiplas oportunidades de tomadas de decisão e ações variadas, torna antes estas últimas possíveis ao invés de causá-las.

Igualmente influenciadas pela ecologia psicológica, Carello et al.37 elaboram, todavia, a questão de outra maneira, levando ainda mais longe a relação organismo-ambiente. As autoras tomam como ponto de partida a definição de inteligência como "comportamento dirigido a um fim, marcado pelo emprego de distinções significativas, tornadas possíveis através de ciclos de percepção-ação"38. Essa definição implica um agente inteligente capaz de fazer uso de distinções significativas de modo a organizar ações apropriadas em relação a elas. Para Carello et al. agência é manifestada em relação ao affordance, conceito fundamental

34 Caberia aqui, desde já, uma explanação sobre a diferença entre reagir e responder. Contudo, resolvi correr o risco de não abordar o assunto ainda neste momento, dado o potencial que essa discussão pode render nos desenvolvimentos posteriores deste trabalho, auferido a partir de vislumbres em: DESPRET, Vinciane. Ethology between empathy, standpoint and perspectivism: the case of the Arabian babblers. Vinciane Despret - D'un texte à l'autre... Bienvenue dans mon cabinet de curiosités en ligne. Publié le 28 avril 20 Io. Disponível em: <vincianedespret.be/2010/04/ethology-between-empathy-standpoint-and-perspectivism-thecase-of-the-arabian-babblers $>$. Acesso em: $28 \mathrm{dez}$. 20I7; HARAWAY, Donna. A partilha do sofrimento: relações instrumentais entre animais de laboratório e sua gente. Horizontes Antropológicos, v. I7, n. 35, jan.-jun., 20II, p. 27-64. Disponível em: <scielo.br/scielo.php?script=sci_arttext\&pid=SoI04-718320II000I00002 >. Acesso em: 28 dez. 20I7; STENGERS, Isabelle. No tempo das catástrofes - resistir à barbárie que se aproxima. São Paulo: Cosac Naify, 2015.

35 CALVO GARZÓN, Paco; KEIJZER, Fred. Plants: adaptive behavior, root-brains, and minimal cognition. Adaptive Behavior, v. I9, n. 3, 20II, p. I55-I7I. http://dx.doi.org/I0.II77/I0597I23II409446.

36 GAGLIANO, Monica. In a green frame of mind: Perspectives on the behavioural ecology and cognitive nature of plants. AoB PLANTS, v. 7, n. I, 20I5, p. I-8. http://dx.doi.org/Io.Io93/aobpla/pluo75.

37 CARELLO, Claudia et al. Unnerving intelligence. Ecological Psychology, v. 24, n. 3, 20I2, p. 24I-264. http://dx.doi. org/I0.I080/I04074I3.20I2.702628.

38 Ibidem, p. 6. 
na ecologia psicológica, como acabamos de ver. Para uma planta ser considerada um agente, ela precisa demonstrar a habilidade de mudar seu comportamento em antecipação ao que acontecerá, reflexivamente ao que aconteceu, e com opções de como agir para atingir determinado fim. Em outras palavras, é necessário que possamos identificar prospectividade, retrospectividade e flexibilidade ao buscarmos exemplos de comportamento em plantas. Aqui, as autoras não estão preocupadas com os mecanismos que poderiam suportar um comportamento inteligente. Ao invés disso, a ênfase é deslocada para os constrangimentos e possibilidades de interação do organismo com o ambiente, e como um age sobre o outro.

Por último, como que aproximando estas últimas abordagens das que apresentei no início deste tópico, Michael Marder ${ }^{39}$ aplica um modelo fenomonológico ${ }^{40}$ focado na atenção, entendida aqui como uma característica da conduta inteligente no presente, pela qual um dado organismo responde seletivamente ao fluxo inconstante e sempre em mudança de estímulos do ambiente de uma maneira que permite manter um nível adequado de adaptação a ele. Segundo Marder, o ato de prestar atenção depende de três elementos inter-relacionados e dinamicamente estruturados: foco ou tematização; contexto; e margem ou horizonte. No caso do comportamento de forrageio, por exemplo, um estímulo no qual a planta precisa focar é a qualidade do solo, que deve ser acessado como precondição para a seleção de um fragmento que seja rico em recursos. Contudo, para focar a atenção em qualquer estímulo determinado, é necessário antes isolá-lo de um contexto no qual se encontra dissolvido. Em plantas, esse processo é multifocal, e as informações são percebidas e registradas por receptores de vários tipos, localizados desde as pontas das raízes até as folhas. Sinalização em plantas envolve, portanto, a coordenação entre múltiplos focos de atenção, cada um deles destacando um pedaço de informação vital acerca das condições ambientais e traduzindo-os em instruções para o crescimento ou reprodução.

\section{CONSTRUINDO UMA “NARRATIVA MAIS RICA” SObRE AS PLANTAS}

Até aqui, é possível observar três tensões muito claras, todas elas muito longe de estarem resolvidas.

I. A primeira é entre os proponentes da NBP, que postulam que as plantas manifestam um comportamento inteligente suportado por mecanismos internos de percepção e processamento de sinais, e aqueles cientistas mais conservadores que,

39 MARDER, Michael. Plant intelligence and attention. Plant Signaling er Behavior, v. 8, n. 5, 20I3, p. I-5.

40 Marder toma como base os trabalhos de: HUSSERL, Edmund. Ideas pertaining to a pure phenomenology and to a phenomenological philosophy, first book. Dordrecht: Kluer, I983; HUSSERL, Edmund. On the phenomenology of the consciousness of internal time. Dordrecht: Kluer, I99I; ARVIDSON, P. Sven. The sphere of attention: context and margin. Dordrecht: Springer, 2006. 
a despeito de reconhecerem o complexo comportamento das plantas, negam-se a atribuir qualquer tipo de inteligência por trás disso, uma vez que os mecanismos e processos envolvidos ainda não estão totalmente esclarecidos, sendo preferível, portanto, ater-se às explicações correntes. Dessa primeira tensão, resta aos proponentes da NBP a acusação de antropormofismo e delírio científico, já que seus críticos consideram inapropriado substituir explicações consolidadas por metáforas imaginativas.

2. A segunda tensão é interna e se traduz em certa ambivalência nos trabalhos dos proponentes e colaboradores da NBP, que, apesar do foco promissor na relação planta-ambiente e da inspiração em um conceito expandido de cognição, não ousam levar o argumento adiante, continuando a investir em uma perspectiva computacional calcada em uma separação entre o ambiente-que-gera-estímulos e o organismo-que-os-processa-e-responde.

3. Por último, temos a tensão entre os proponentes da NBP e outros cientistas dedicados ao tema da inteligência das plantas, que, no intuito de escapar das duas tensões anteriores, desenvolvem análises apoiadas em uma perspectiva não algorítmica, com enfoque na percepção dos sinais e ação das plantas no ambiente, deixando em segundo plano, ou mesmo rejeitando, a necessidade de mecanismos específicos para suportar um comportamento inteligente.

Articularei essas tensões destacando os elementos do que Hustak \& Myers ${ }^{4 \mathrm{I}}$ chamam de uma "narrativa mais rica". A ideia é ir além do enfoque redutivo da biologia contemporânea sobre células e genes, ou de uma lógica evolucionista neodarwiniana exclusivamente adaptacionista, e procurar dar maior atenção ao organismo, seu comportamento e seus modos de relação. Busco, com isso, uma narrativa que dê conta do modo como as plantas se expressam e permita desvelar os emaranhados nos quais plantas e cientistas estão envolvidos. Minha hipótese é a de que essas tensões, sozinhas ou combinadas, sugerem modos de acessar a perspectiva das plantas ${ }^{42}$.

Usarei aqui uma solução - que pode ser entendida tanto no sentido da química como de maneira mais convencional, de alternativa a um problema - para transformar e intensificar o sabor dessas tensões. A inspiração para essa alquimia vem das ideias introduzidas no campo interespecífico pelas etnografias multiespécies ${ }^{43}$. Longe de

4I HUSTAK, Carla; MYERS, Natasha, op. cit.

42 Com "perspectiva das plantas", não quero sugerir aqui uma perspectiva autônoma, mas justamente uma perspectiva situada nos emaranhados, no cruzamento de múltiplos pontos de vista. Essa perspectiva é, portanto, relacional e emerge de modo diferente a cada momento, sendo também, nesse sentido, situacional, transitória e efêmera. O que estou tentando dizer, seguindo uma intuição, confesso, é que a perspectiva se desloca para o outro. Esse outro irá informar, comunicar - ou mesmo enunciar - a perspectiva de determinado agente. Aqui, no caso, a perspectiva das plantas é deslocada para os cientistas, que a enunciam (ficamos com esse?) de diferentes maneiras. O que as plantas enunciam sobre a perspectiva dos cientistas - através de sua linguagem química ou da troca de informações via micorriza - eu não sei, mas acredito ser possível saber.

43 KIRKSEY, Eben; SCHUETZE, Craig; HELMREICH, Stefan. Introduction. Tactics of multispecies ethnography. In: KIRKSEY, Eben (Ed.). The Multispecies Salon. Durham: Duke University Press, 20Io, p. I-24. 
se constituir como uma escola de pensamento unificada, mas uma tendência que emergiu nos últimos anos - de acordo com algumas de suas principais vozes - "como a atividade de um enxame, uma rede sem um centro para ditar a ordem, povoada por uma multidão de diferentes agentes criativos"44, os etnógrafos multiespécies estão preocupados com os efeitos de nossos emaranhamentos com outros tipos de seres vivos, estudando a variedade de organismos cujas vidas e mortes estão ligadas aos mundos sociais humanos. Na busca por melhores métodos para esse campo emergente, discutem também o que táticas artísticas e equipamentos de laboratórios biológicos podem acrescentar às práticas etnográficas existentes ${ }^{45}$.

Aqui, a condição humana é entendida com base na lógica coevolutiva e na relação interconstitutiva entre as espécies. Nesse sentido, a biologia humana e a cultura humana - não importa como os dois aspectos estejam divididos conceitualmente emergem a partir dessas relações. Nesse processo, todas as partes agem umas sobre as outras, nenhuma delas ocupando um lugar privilegiado. Mesmo que os humanos possam ter uma ideia de como agir e transformar o mundo, ainda assim essas ideias surgem ao longo de uma rede de interações, e as transformações são realizadas apenas "na superfície", enquanto diversas agências são postas em confluência, cada uma dando sua própria contribuição no modo como as coisas tomam forma ${ }^{46}$.

Independentemente de como o encaramos, o fato de o debate sobre as capacidades agentivas das plantas estar em curso e bastante vivo entre praticantes dos diferentes ramos das ciências das plantas aponta para mais um capítulo de uma história que vem sendo escrita desde o século passado, quando as nítidas fronteiras que separavam os humanos dos outros animais - nossos monopólios da linguagem, raciocínio, fabricação de ferramentas, cultura e até mesmo autoconsciência - foram borradas, uma após a outra, à medida que a ciência reconhecia essas faculdades em outros animais. No que diz respeito às plantas, nos últimos anos, tem tido lugar um movimento que pode ser descrito como "a virada das plantas"47, uma atenção geral por parte de filósofos, antropólogos, escritores de ciência e pensadores de maneira geral para as vidas desses organismos.

Parte da atenção que a NBP angariou se deve a isso, mas não apenas. A NBP traz dados sólidos sobre a capacidade agentiva das plantas, obtidos a partir de experimentos conduzidos por áreas de estudo firmadas e respeitadas nas ciências das plantas, ajudando a construir, desse modo, a partir de sua posição no meio científico, uma nova maneira de se olhar para as plantas. Ao considerá-las como mais do que criaturas passivas ou seres autômatos, e reconhecendo que elas são

44 KIRKSEY, Eben; HELMREICH, Stefan. The emergence of multispecies ethnography. Cultural Anthropology, v. 25, n. 4, 20I0, p. 545-576. http://dx.doi.org/I0.IIII/j.I548-I360.20I0.0I069.x.

45 Ibidem, p. 546.

46 VAN DOOREN, Thom. Wild seed, domesticated seed: companion species and the emergence of agriculture.

PAN: Philosophy, Activism, Nature, v. 9, n. 9, 20I2, p. 22-28.

47 MYERS, Natasha. Conversations on plant sensing: notes from the field. Natureculture, 20I5, p. 35-66. 
organismos inteligentes, capazes de aprender, de tomar decisões e agir em relação às situações que enfrentam no ambiente, os proponentes da NBP vêm contribuindo na reformulação dessas definições para além de suas bordas antropocêntricas, procurando o significado desses termos quando pensados no contexto do modo de vida e das relações das plantas com o mundo.

Contudo, esse esforço não os isenta da acusação de antropomorfismo, como muito bem apontam seus críticos mais ferrenhos. Devemos, entretanto, fazer uma ressalva a essa crítica: como revela Myers, antropomorfizar nunca é um exercício de mão única. Em seu trabalho, a autora empreendeu uma série de conversas com cientistas que estudam, a partir de perspectivas variadas, os processos de sinalização em plantas, evidenciando a partir de seus discursos e da observação de suas práticas cotidianas como, no processo cuidadoso de trabalho em suas pesquisas, esses praticantes da ciência aprendem a prestar atenção nas mesmas coisas que as plantas: na mais sutil alteração no gradiente de nutrientes do solo; nas mínimas mudanças nas fragrâncias químicas na atmosfera envolvente; nas reconfigurações nas redes de relações com bactérias, fungos, polinizadores, herbívoros e outras plantas. Para que o trabalho corra bem, percebe a autora, os cientistas devem entregar-se à sua investigação. Eles devem se deixar levar pelos comportamentos, ritmos e temporalidades das plantas, e devem aprender a descobrir e observar uma gama de fenômenos que muitas outras pessoas talvez jamais poderão ver. Através de seus instrumentos e experiências, os cientistas se enredam completamente com as plantas que estudam ${ }^{48}$.

As conversas com esses praticantes da ciência revelaram, segundo as impressões de Myers ${ }^{49}$, diversos tipos de ambiguidades, "escorregões" e atribuição de agência aos organismos não humanos, assim como uma notável oscilação entre encantamento e desencantamento em suas falas. Eles pareciam, conta a autora, estar sendo puxados, de um lado, por visões quase transcendentais sobre as maravilhosas destrezas sensoriais das plantas, e, de outro, pelo desencantamento forçado por um "estilo de pensamento" reducionista e mecanicista que resiste em imputar qualquer agência aos organismos não humanos. Quando paravam de policiar seus vocabulários e deixavam livres suas imaginações, deixavam entrever todo o encantamento em suas falas sobre as formas de agência e intencionalidade nas plantas. Apesar das ardentes tentativas de restringir suas linguagens e aderir às convenções de suas publicações científicas, as plantas em suas falas se recusavam a ser contidas. Mais do que oferecer oportunidades de intervenção etnográfica, conclui a autora, essas oscilações entre encantamento e desencantamento lhe deram a oportunidade de perceber como o antropomorfismo não é apenas uma imposição unidirecional de conceitos e valores humanos aos organismos não humanos, mas uma maneira de se envolver em mundos e perspectivas outras que os formam.

Assim, essa espécie de antropomorfismo não antropocêntrico, se me permitem o trocadilho, presente nas ideias que orientam a NBP e produzido pela primeira tensão que descrevi anteriormente, pode ser entendido como uma maneira de acessar a perspectiva das plantas, que se desenvolve no contato íntimo entre plantas e

\footnotetext{
48 Ibidem.

49 Ibidem.
} 
cientistas durante suas pesquisas e experimentos. Porém, mesmo que isso não envolva necessariamente uma contradição, o ponto de vista computacional e representacionalista que têm do modo como as plantas interagem com o ambiente - seja invocando um sistema de percepção, comunicação e respostas integrados análogo a um sistema nervoso, ou capacidades racionais como, por exemplo, análises de custo e benefício ${ }^{50}$ - instaura certa ambiguidade no modo como os proponentes da NBP interpretam a maneira pela qual as plantas percebem e agem no mundo, remetendo à segunda tensão, de cunho interno. Foi no intuito de escapar dessa ambiguidade que os protagonistas da terceira tensão desenvolveram suas ideias. Trata-se, lembrando, de outros trabalhos sobre a inteligência das plantas que deixam em segundo plano, ou mesmo rejeitam, a necessidade de mecanismos específicos para suportar um comportamento inteligente.

A ideia que orienta esses trabalhos é a de que organismo e ambiente não são domínios distintos, mas se constituem mutuamente através de ciclos de percepção-ação. Não há, de maneira separada, um ambiente-que-gera-estímulos e um organismo-que-os-processa-e-responde, ambos os processos ocorrem simultaneamente e influenciam-se, fazendo e desfazendo um ao outro continuamente. Se a primeira tensão produz uma maneira de acessar a perspectiva das plantas a partir do envolvimento recíproco com os cientistas que as estudam, aqui, a planta manifesta sua perspectiva efetivamente através dos modos de relação que estabelece e dos estados pelos quais se apresenta: uma planta é o que percebe, e percebe o mundo a partir do que ela é. $\mathrm{O}$ acesso a essa perspectiva leva em direção a uma fenomenologia, como colocado por Marder, mas cuja inspiração vem do clássico da etologia Jakob von Uexkülls5.

É assim que, segundo Marder $^{52}$, a morfologia sempre em desenvolvimento das plantas expressa objetivamente seus atos de atenção ao longo do tempo, na medida em que seu corpo se ajusta às condições do ambiente. As decisões são tomadas na interseção entre o processamento de informações locais e uma rede global de sinalização, sintonizada ao mesmo tempo com os fatores ambientais externos e as necessidades fisiológicas e de desenvolvimento da planta. De modo similar, a estrutura modular das raízes e galhos, bucando o crescimento ótimo, reflete espacialmente a interação entre os diferentes níveis de atenção nas plantas. Por sua vez, cada momento no desenvolvimento, cada nova configuração engedra modos de atenção determinados pelo novo horizonte de experiências, e por conseguinte novos modos de relação com o ambiente, novas oportunidades de captar recursos ou se reproduzir conforme novos pontos focais são acrescentados à esfera da atenção.

Mesmo tratando de coisas diferentes, não quer dizer que esses dois modos de acessar a perspectiva das plantas sejam inconciliáveis. Despret ${ }^{53}$ oferece uma

50 TREWAVAS, Anthony, 2003, op. cit., p. 4 .

5I VON UEXKÜLL, J. (I934). A stroll through the worlds of animals and men - a picture book of invisible worlds,

[s.l: s.n.]. In: SCHILLER, Claire H. (Ed.). Instinctive behavior - the development of a moderne concept. New York: International Universities Press, I964, p. 5-80.

52 MARDER, Michael, op. cit., p. 3.

53 DESPRET, Vinciane. From secret agents to interagency. History and Theory, v. 52, 2013, p. 29-44. 
leitura deleuziana capaz, ao meu ver, de aproximá-los. Seja na interação entre planta e cientistas, ou entre planta e os múltiplos fatores do ambiente, estamos falando de emaranhados onde as fronteiras entre agente e sujeito são desafiadas. Esses emaranhados podem ser compreendidos em termos de agenciamentos. Um agenciamento, explica Despret ${ }^{54}$, é uma relação de forças - no sentido do poder de afetar outras forças com as quais é posta em relação, e por sua vez ser afetado por elas - que torna alguns seres capazes de fazer tornar outros seres capazes, de maneira plurivocal, de modo que o agenciamento resiste a ser desmembrado, resiste a contornos claros. O que constitui o agente e aquele que sofre a ação é distribuído e redistribuído incessantemente. Agência é, desse modo, produto de agenciamentos. Há, em cada agenciamento, coanimação, no sentido literal, isto é, no sentido mais animista do termo. Incitar, provocar, acionar, inspirar são exemplos de afetos ativos dentro de um agenciamento; um afeto reativo é entendido em termos da capacidade de ser incitado, inspirado, acionado ou provocado, ou de ser induzido a produzir - e mesmo em termos do poder de dar a outro ser o poder de afetar.

Assim, podemos supor que a perspectiva de determinada planta está justamente nos emaranhados confusos nos quais se envolve - e desse modo é instável, transitória, efêmera e multifacetada - e precisa ser construída, ou melhor, reconstituída tendo isso em mente. Nós possuímos objetivamente a capacidade de acessar e expressar a perspectiva das plantas a partir dos diversos níveis de envolvimento que estabelecemos, na medida em que as deixamos nos afetar e nos deixamos emaranhar. Isso é muito diferente de meramente falar por elas.

\section{“FITOMORFISMO”. OU TODO ANTROPOMORFISMO É TAMBÉM ALGUM-OUTRO-MORFISMO}

Em Há mundo por vir? Ensaio sobre os medos e os fins ${ }^{55}$, ao discorrerem sobre a diferença entre o par conceitual natureza/humanidade tal como pensado pelos povos ameríndios e pela filosofia ocidental de maneira geral, Danowski e Viveiros de Castro afirmam que o postulado fundamental das cosmopolíticas ameríndias é o que costumamos designar de antropomorfismo. O conceito, para eles, contudo, não deveria ser de modo algum utilizado de modo pejorativo, como costumamos ver por aí (a acusação de antropomorfismo destinada aos proponentes e colaboradores da NBP reflete uma atitude geral na ciência moderna em restringir ao máximo o uso desse recurso), mas deveria ao invés disso "receber cidadania filosófica plena, apontando para possibilidades conceituais ainda inexploradas"56.

Assim, os autores definem as ontologias "animistas" (aspas dos autores) dos ameríndios como manifestando o "princípio antropomórfico", contrastando este com o "princípio antropocêntrico", enraizado mais fixamente na metafísica ocidental. O

54 Ibidem, p. 38.

55 DANOWSKI, D.; VIVEIROS DE CASTRO, E. Há mundo por vir? Ensaio sobre os medos e os fins. Desterro

[Florianópolis]: Cultura e Barbárie/Instituto Socioambiental, 2014.

56 Ibidem, p. 97. 
primeiro não é apenas bastante diferente do segundo, explicam, mas uma "inversão irônica completa"57 deste:

Dizer que tudo é humano é dizer que os humanos não são uma espécie especial, um evento excepcional que veio interromper magnífica ou tragicamente a trajetória monótona da matéria no universo. O antropocentrismo, inversamente, faz dos humanos uma espécie animal dotada de um suplemento transfigurador; ele os toma por seres atravessados pela transcendência como se por uma flecha sobrenatural, marcados por um estigma, uma abertura ou falta privilegiada (felix culpa) que os distingue indelevelmente no seio - no centro - da Natureza ${ }^{58}$.

Com base nisso, um antropomorfismo não antropocêntrico seria, então, além de uma expressão inadvertidamente redundante utilizada por mim, justamente esse tipo de antropomorfismo que prolifera empaticamente o escopo do humano, transformando todo o potencial dos modos de relação estabelecidos a partir disso, sem criar o tipo de excepcionalismo que coloca a espécie acima ou além dos demais seres que povoam o que convencionamos chamar de natureza.

É nesse mesmo sentido que Natasha Myers aborda a questão. A partir de uma leitura perspicaz de um dos escritos de Darwin acerca da reprodução das orquídeas ${ }^{59}$, a autora identifica uma passagem em que o naturalista move o próprio corpo para simular as distintas posições dos órgãos sexuais de diferentes orquídeas do gênero Catasetum e comunicá-las aos leitores, realizando o que a autora chama de um "experimento corporal"6o. O que poderia ser mais um antropomorfismo como outro qualquer, que compara de alguma forma as plantas ao humano, revela-se mais do que isso ao considerarmos que Darwin está mimeticamente emaranhado com as orquídeas durante o experimento. Ao se deixar mover pelas formas através das quais as plantas se apresentam, os contornos de seu corpo humano são deslocados e descentralizados ao mesmo tempo que nele se reinscrevem aqueles pertencentes às orquídeas ${ }^{61}$. Esse exemplo, relata Myers ${ }^{62}$, ajudou-a entender que o que chamamos de antropomorfismo pode realmente ser evidência de nossa capacidade e vontade de nos abrir para os outros, para assim permitir que outros modos de incorporação flexionem e transformem os nossos próprios.

Esse mesmo fenômeno é notado por Myers em outro trabalho, resultado de suas pesquisas durante anos com modeladores de proteínas, cujas experiências corporais, conforme observado pela autora, são ressonantes com as de Darwin e durante as quais os cientistas não apenas antropomorfizavam suas moléculas, mas também

\section{Ibidem.}

58 Ibidem.

59 DARWIN, Charles. On the various contrivances by which British and foreign orchids are fertilised by insects: and on the good effects of intercrossing. London: J. Murray, I862.

60 MYERS, Natasha. Conversations on plant sensing..., op. cit., p. I8.

6I Ibidem.

62 Ibidem, p. 24 . 
se "molecularizavam" no processo ${ }^{63}$. Nessa mesma perspectiva, embora na ocasião não tenha colocado exatamente nesses termos, em um breve texto Myers convida o leitor a "cultivar sua planta interior", "vegetalizar" seu corpo, que "já é mais que humano". Para isso, diz ela, é necessário criar um interesse profundo e se envolver afetivamente com as mesmas coisas com as quais as plantas se envolvem, segui-las, deixar-se seduzir pelos seus movimentos trópicos e assim adquirir destrezas sensoriais renovadamente vegetalizadas ${ }^{64}$. Mais tarde, em um texto no qual a autora desenvolve uma reflexão a partir de uma série de encontros e conversas com cientistas que estudam plantas, e ao qual me referi anteriormente, Myers fala de uma "fitomorfização" 5 dos cientistas, seguindo a mesma chave de análise apresentada nos textos anteriores.

\section{CONSIDERAÇões FINAIS: CAMINHOS PARA UMA CIÊNCIA REANIMADA}

Ao atribuir tais faculdades agentivas às plantas, a NBP estaria praticando algo como um pensamento animista, como dão a entender os seus críticos? Seria possível, na perspectiva oferecida pelos adeptos da NBP, nós, humanos, nos comunicarmos com as plantas? Poderíamos entender o que elas têm a nos dizer a partir das formas como elas se expressam? Tentei, de maneira muito tímida, indicar caminhos e apresentar pistas com as quais me deparei para responder a essas questões. Para finalizar, gostaria de resgatar uma discussão proposta por Ingold. Mesmo estando ciente da crítica levantada por esse autor à proposta das etnografias multiespécies, crítica que

63 Idem. Rendering life molecular: models, modelers, and excitable matter. Durham, NC: Duke University Press, 2015 .

64 Idem. Sensing botanical sensoria:a kriya for cultivating your innerplant. Centre for Imaginative Ethnography, 20I4, p. I-6. Disponível em: <imaginativeethnography.org/imaginings/affect/ sensingbotanical-sensoria $>$. Acesso em: 28 dez. 2017.

65 Idem. Conversations on plant sensing..., op. cit. 
se tornou central nos debates acerca do campo ${ }^{66}$, sua leitura em uma conferência realizada originalmente na Universidade de Aberdeen em $201 \mathrm{II}$ traz algumas ideias que me inspiraram a escrever este texto e a pensar minha atual pesquisa.

Nessa ocasião, Ingold discorre sobre o emudecimento da natureza, corolário máximo de um processo iniciado na Reforma, que instaurou uma mudança nas formas de ler o mundo, uma separação entre o significado imanente das coisas e suas posteriores interpretações. O mundo que, antes, na ontologia medieval, era conhecido através de um processo de desvelamento gradual, no qual o engajamento perceptivo do conhecedor apreendia e o construía simultaneamente, passou a ser um repositório de dados, pronto para ser decifrado, bastasse dispor das chaves corretas para acessá-lo. Porém, diz o autor, mesmo silenciado, o mundo, ou a natureza, "pode ser - e geralmente o é - um lugar tão barulhento que chega a ser ensurdecedor"

Entretanto, para o filósofo Steven Vogel, citado por Ingold, mesmo com todo o barulho advindo dessa natureza ricamente sonora, nada indica que as entidades naturais conversem entre si, e muito menos com os humanos. Qualquer conversa que possa existir é um mero ato de ventriloquia, uma projeção de nossas próprias palavras em um objeto mudo. Nesse sentido, Vogel está mais próximo dos críticos da NBP, uma vez que essa acusação, que se traduz pela repulsa científica ao antropomorfismo, é dirigida a todos aqueles que buscam uma compreensão mais empática com os seres não humanos. Em contrapartida, Nicole Klenk, também citada por Ingold, desafia essa acusação, defendendo que os "não humanos podem $e$, sim, respondem à voz, aos gestos e à presença humana, de forma que faz sentido para eles e para nós"68. Ao colocar em palavras o que a natureza está dizendo, os seres humanos seriam antes tradutores do que ventríloquos. Para a autora, é exatamente nisso que consiste o

66 Ver: INGOLD, Tim. Anthropology beyond humanity. Suomen Antropologi: Journal of the Finnish Anthropological Society, v. 38, n. 3, 20I3, p. 5-22; e a resposta de Kirksey em: KIRKSEY, Eben. Species: a praxiographic study. Journal of the Royal Anthropological Institute, (N.S.), 2I, 20I5, p.758-780. Em linhas gerais, Ingold aponta que, além de um anacronismo - a atenção etnográfica ao mundo mais que humano não é novidade alguma na antropologia, podendo ser mapeada em trabalhos desde os anos I960 -, a ênfase que as etnografias multiespécies dão ao próprio conceito de espécie remete a uma pretensão ontológica universalista e uma imposição antropocêntrica. Em outras palavras, Ingold acusa os etnógrafos multiespécies de endossar as separações inerentes a uma ontologia do tipo naturalista, por assim dizer. Kirsey responde à crítica de maneira arguta em um artigo robusto apoiado em dados de sua etnografia - uma praxiografia na verdade, mas não irei entrar nos meandros desse conceito aqui - entre cientistas que trabalham com taxonomia em diferentes instituições científicas. $\mathrm{O}$ autor mostra que o conceito de espécie está longe de ser uma ideia universal em biologia. Através da observação cuidadosa das práticas envolvendo o trabalho em taxonomia, Kirksey propõe que cientistas não simplesmente fazem ou constroem espécies, mas evidenciam os devires nos quais estas emergem como emaranhados em redes ecológicas, políticas e econômicas. Nesse sentido, para o autor, reconhecer e nomear espécies é um imperativo ético que abre desafios epistemológicos, técnicos e ontológicos, na medida em que tornar visíveis seres que antes existiam independentemente de nós fomenta novos modos de interdependência.

67 INGOLD, Tim. Walking with dragons: an anthropological excursion on the wild side. ASA Firth Lecture, 2OII, p. I-29.

68 KLENK apud INGOLD, Tim, 20II, op cit., p.27. 
trabalho científico, fundado em uma interação cuidadosa com (e uma observação dos) os componentes do mundo natural ${ }^{6}$.

A concepção ingoldiana da vida como um emaranhado de linhas em crescimento e movimento não está muito longe da concepção animista do mundo, porém, diferente do animismo como uma lógica classificatória desenvolvido por Descola, no qual as pessoas se valem das categorias oriundas da prática social para pensar a relação com os objetos naturais, Ingold defende que o animismo é antes uma ontologia: não meramente um sistema de crenças que atribui vida ou espírito a coisas que são verdadeiramente inertes, mas uma maneira de estar no mundo, ou estar vivo para o mundo.

[...] A animacidade, portanto, não é uma propriedade das pessoas imaginariamente projetada sobre as coisas pelas quais se percebem cercadas. Em vez disso - e este é o meu segundo ponto -, trata-se do potencial dinâmico, transformador de todo o campo de relações dentro do qual seres de todos os tipos [...] contínua e reciprocamente trazem uns aos outros à existência. A animacidade do mundo da vida, em suma, não é o resultado de uma infusão de espírito na substância, ou de agência na materialidade, mas é, ao contrário, ontologicamente anterior à sua diferenciação ${ }^{70}$.

Nessa concepção de mundo, os seres não são entidades discretas em relação uns com os outros, mas um emaranhado de linhas em perpétuo crescimento e movimento. Não há começo ou fim determinados, as linhas seguem serpenteando por entre o meio, como a raiz de uma árvore, com múltiplas direções e ramificações. Ao invés de conexões entre os pontos, temos um entrelaçamento de linhas, ou uma malha. "Na ontologia anímica, os seres não ocupam simplesmente o mundo, eles o habitam, e ao fazê-lo - costurando seus próprios caminhos através da malha contribuem para a sua trama em constante evolução" ${ }^{\text {T. }}$.

Em relação à percepção humana, as plantas constituem um tipo radical de alteridade. Elas dificilmente se movem e além disso não emitem sons em frequências que podemos facilmente captar. Isso pode criar, para muita gente - embora eu não tenha claro quem exatamente seriam essas pessoas -, uma impressão de passividade do mundo vegetal. Os neurobiólogos das plantas contestam essa visão e vêm indicando que as plantas não são apenas vítimas das circunstâncias, mas antes organismos ativos no ambiente. Para os cientistas da NBP, os dados levantados e a interpretação dos mesmos não parecem estar radicalmente separados, como é

69 Mesmo inclinado a concordar com Klenk, a coisa não é tão simples. A interação de que fala a autora e que fundamenta a prática científica pode ser colocada também nos termos usados por: ALMEIDA, Mauro W. Barbosa. Caipora e outros conflitos ontológicos. Revista de Antropologia da UFSCar, v. 5, n. I, jan.-jun. 20I3, p. 7-28. Ontologias múltiplas convivem, muitas vezes incompatíveis entre si, outras vezes concordando quanto a certos critérios parciais de verdade. Assim, os encontros no âmbito fenomenológico são na maioria das vezes ambíguos quanto ao tipo de ontologia que lhes confere sentido.

70 INGOLD, Tim. Repensando o animado, reanimando o pensamento. In: Estar vivo: ensaios sobre movimento, conhecimento e descrição. Petrópolis: Vozes, 2015 (Coleção Antropologia).

7 I Ibidem. 
comum na prática científica moderna, mas antes trabalhados juntos a partir de uma retórica particular, que não vê problema no uso de metáforas e analogias na construção de um conhecimento sobre os processos da vida, possibilitando, assim, uma abertura animista capaz de oxigenar a prática científica.

A ciência, diz Ingold, "tal como está, repousa sobre uma impossível fundação, pois, a fim de transformar o mundo em um objeto de preocupação, ela tem que colocar-se acima e além do próprio mundo que ela afirma entender"72. Nesse sentido, a NBP oferece a oportunidade de pensarmos outras práticas possíveis dentro da ciência e desenvolvermos novas narrativas, fundadas em uma abertura para o mundo da vida e em uma maior empatia com os seres. Essa empatia é mais que necessária em tempos de extinções, nos quais estarmos alertas de que as vidas e mortes de outros seres estão implicadas em nossa existência é um passo importante para começarmos a desenvolver práticas mais responsáveis - e responsivas, como colocado por Haraway ${ }^{73}$ - de intervenção e sobrevivência.

\section{SOBRE O AUTOR}

GUILHERME HENRIQUES SOARES é mestrando/ bolsista Capes no Programa de Pós-Graduação em Antropologia Social da Universidade Federal do Amazonas (PPGAS/UFAM) e pesquisador do Núcleo de Estudos da Amazônia Indígena (Neai).

E-mail: ghsoares24@gmail

\section{REFERÊNCIAS BIBLIOGRÁFICAS}

ALMEIDA, Mauro W. Barbosa. Caipora e outros conflitos ontológicos. Revista de Antropologia da UFSCar, v. 5, n. I, jan.-jun., 2013, p. 7-28.

ALPI, Amedeo et al. Plant neurobiology: no brain, no gain?. Trends in Plant Science, v. I2, n. 4, 2007, p. I35I36. http://dx.doi.org/Io.IoI6/j.tplants.2007.03.002.

ARVIDSON, P. Sven. The sphere of attention: context and margin. Dordrecht: Springer, 2006.

BABIKOVA, Zdenka et al. Underground signals carried through common mycelial networks warn neighbouring plants of aphid attack. Ecology Letters, v. I6. n. 7, 20I3, p. I-9. http://dx.doi.org/Io.III/ele.I2II5. BALUŠKA, František et al. Neurobiological view of plants and their body plan. In: BALUŠKA, F; MANCUSO; F.; VOLKMANN, D. (Org.). Communication in plants: neuronal aspects of plant life. Germany: Springer, 2006, cap. 2, p. I9-35.

72 Ibidem.

73 HARAWAY, Donna, op. cit. 
BALUŠKA, František et al. The root-brain hypothesis of Charles and Francis Darwin. Plant Signaling er Behavior, v. 4, n. I2, 2009, p. II2I-II27.

BALUŠKA, František; MANCUSO, Stefano. Plant neurobiology as a paradigm shift not only in the plant sciences. Plant Signaling er Behavior, v. 2, n. 4, 2007, p. 205-207.

;___. Plant neurobiology: from sensory biology, via plant communication, to social plant behavior.

Cognitive Processing, v. Io, n. I, 2009, p. 3-7. http://dx.doi.org/Io.I007/sI0339-008-0239-6.

;___. Plant neurobiology. From stimulus perception to adaptive behaviour of plants, via integrated chemical and electrical. Plant Signaling e\& Behavior, v. 4, n. 6, 2009, p. 475-476.

BARLOW, Peter W. Reflections on plant neurobiology. BioSystems, v. 92, n. 2, 2008, p. 132-I47. http://dx.doi. org/Io.IoI6/j.biosystems.2008.01.004.

BATESON, Gregory. Mind and nature. A necessary unity. London: Fontana, I985.

BRENNER, Eric et al. Plant neurobiology: an integrated view of plant signaling. Trends in Plant Science, v. II, n. 8, 2006, p. 4I3-4I9. http://dx.doi.org/Io.IOI6/j.tplants.2006.06.009.

BRENNER, Eric et al. Response to Alpi et al.: Plant neurobiology: the gain is more than the name. Trends in Plant Science, v. I2, n. 7, 2007, p. 285-286. http://dx.doi.org/Io.IoI6/j.tplants.2007.03.002.

CALVO GARZÓN, Paco; KEIJZER, Fred. Plants: adaptive behavior, root-brains, and minimal cognition. Adaptive Behavior, v. I9, n. 3, 20II, p. I55-I7I. http://dx.doi.org/Io.II77/I0597I23II409446.

CARELLO, Claudia et al. Unnerving intelligence. Ecological Psychology, v. 24, n. 3, 20I2, p. 24I-264. http:// dx.doi.org/Io.I080/I04074I3.20I2.702628.

CVRCKOVÁ, Fatima; LIPAVSKÁ, Helena; ZÁRSKÝ, Viktor. Plant intelligence: why, why not or where?. Plant Signaling Behavior, v. 4, n. 5, 2009, p. 394-399.

DANOWSKI, D.; VIVEIROS DE CASTRO, E. Há mundo por vir? Ensaio sobre os medos e os fins. Desterro [Florianópolis]: Cultura e Barbárie/Instituto Socioambiental, 20I4.

DARWIN, Charles. On the various contrivances by which British and foreign orchids are fertilised by insects: and on the good effects of intercrossing. London: J. Murray, I862.

DESPRET, Vinciane. Ethology between empathy, standpoint and perspectivism: the case of the Arabian babblers. Vinciane Despret - D'un texte à l'autre... Bienvenue dans mon cabinet de curiosités en ligne. Publié le 28 avril 20Io. Disponível em: <vincianedespret.be/20Io/o4/ethology-between-empathy-standpoint-and-perspectivism-the-case-of-the-arabian-babblers >. Acesso em: $28 \mathrm{dez}$. $20 \mathrm{7}$.

. From secret agents to interagency. History and Theory, v. 52, 2013, p. 29-44.

FIRN, Richard. Plant intelligence: an alternative point of view. Annals of Botany, v. 93, 2004, p. 345-35I. http://dx.doi.org/Io.I093/aob/mcho58.

GAGLIANO, Monica. In a green frame of mind: perspectives on the behavioural ecology and cognitive nature of plants. AoB PLANTS, v. 7, n. I, 20I5, p. I-8. http://dx.doi.org/I0.I093/aobpla/pluo75.

GARZÓN, Francisco Calvo. The quest for cognition in plant neurobiology. Plant Signaling e Behavior, v. 2, n. 4, 2007, p. 208-2II.

HARAWAY, Donna. A partilha do sofrimento: relações instrumentais entre animais de laboratório e sua gente. Horizontes Antropológicos, v. I7, n. 35, jan./jun., 20II, p. 27-64 Disponível em: <scielo.br/scielo. php?script=sci_arttext\&pid=SoI04-718320II000I00002 >. Acesso em: 28 dez. 2017.

HUSSERL, Edmund. Ideas pertaining to a pure phenomenology and to a phenomenological philosophy, first book. Dordrecht: Kluer, I983.

On the phenomenology of the consciousness of internal time. Dordrecht: Kluer, I99I.

HUSTAK, Carla; MYERS, Natasha. Involutionary momentum: affective ecologies and the sciences of plant/insect encounters. Differences: A Journal of Feminist Cultural Studies, v. 23, n. 5, 20I2, p. 74-II8. http://dx.doi.org/IO.I2I5/I040739I-I892907. 
INGOLD, Tim. Walking with dragons: an anthropological excursion on the wild side. ASA Firth Lecture, 20II, p. I-29.

. Anthropology beyond humanity. Suomen Antropologi: Journal of the Finnish Anthropological Society, v. 38, n. 3, 20I3, p. 5-22. Disponível em: <wcaanet.org/downloads/dejalu/feb_20I5/ingold.pdf >. Acesso em: 28 dez. 2017 .

. Repensando o animado, reanimando o pensamento. In: Estar vivo: ensaios sobre movimento, conhecimento e descrição. Petrópolis: Vozes, 2015 (Coleção Antropologia).

KARPIŃSKI, Stanislaw; SZECHYŃSKA-HEBDA, Magdalena. Secret life of plants: from memory to intelligence. Plant Signaling er Behavior, v. 5, n. II, 20IO, p. I39I-I394.

KIRKSEY, Eben. Species: a praxiographic study. Journal of the Royal Anthropological Institute, (N.S.), 2I, 20I5, p. 758-780.

KIRKSEY, Eben; HELMREICH, Stefan. The emergence of multispecies ethnography. Cultural Anthropology, v. 25, n. 4, 20I0, p. 545-576. http://dx.doi.org/Io.IIII/j.I548-I360.20I0.0I069.x.

KIRKSEY, Eben; SCHUETZE, Craig; HELMREICH, Stefan. Introduction. Tactics of multispecies ethnography. In: KIRKSEY, Eben (Ed.). The Multispecies Salon. Durham: Duke University Press, 20Io, p. I-24.

MARDER, Michael. Plant intelligence and attention. Plant Signaling e Behavior, v. 8, n. 5, 20I3, p. I-5.

MATURANA, Humberto; VARELA, Francisco. Autopoieses and cognition. Dordrecht: the Netherlands, I990.

MYERS, Natasha. Sensing botanical sensoria: a kriya for cultivating your inner plant. Centre for Imaginative Ethnography, 20I4, p. I-6. Disponível em: <imaginativeethnography. org/imaginings/affect/sensing-botanical-sensoria> Acesso em: 28 dez. 2017.

. Conversations on plant sensing : notes from the field. Natureculture, 20I5, p. 35-66.

. Rendering life molecular: models, modelers, and excitable matter. Durham, NC: Duke University Press, 20I5.

STAHLBERG, Rainer. Historical overview on plant neurobiology. Plant Signaling e Behavior, v. I, n. I, 2006, p. 6-8.

STENGERS, Isabelle. No tempo das catástrofes - resistir à barbárie que se aproxima. São Paulo: Cosac Naify, 2015 .

STENHOUSE, David. The evolution of intelligence - a general theory and some of its implicantions. London: George Allen and Unwin, I974.

STRUIK, Paul et al. Plant neurobiology and green plant intelligence: science, metaphors and nonsense. Journal of the Science of Foof and Agriculture, v. 88, n. 3, 2008, p. 363-370. http://dx.doi.org/I0.I002/ jsfa.3I3I.

TREWAVAS, Anthony. Aspects of plant intelligence. Annals of Botany, v. 92, n. I, 2003, p. I-20. http://dx.doi. org/Io.I093/aob/mcgioI.

. Aspects of plant intelligence: an answer to Firn. Annals of Botany, v. 93, n. 4, 2004, p. 353-357. http:// dx.doi.org/Io.I093/aob/mch059.

. A brief history of systems biology. The Plant Cell, v. I8, n. I0, 2006, p. 2420-2430. http://dx.doi. org/IO.II05/tpc.I06.042267.

. Response to Alpi et al.: Plant neurobiology - all metaphors have value. Trends in Plant Science, v. I2, n. 6, 2007, p. I-3. http://dx.doi.org/Io.IoI6/j.tplants.2007.04.006.[TREWAVAS, Anthony; BALUŠKA, František. The ubiquity of consciousness. Embo Reports, v. I2, n. I2, 20II, p. I22I-I225. http://dx.doi. org/IO.I038/embor.20II.2I8.

TREWAVAS, Tony. Plant intelligence: an overview. BioScience, v. 66, n. 7, 20I6, p. 542-55I. http://dx.doi. org/Io.I093/biosci/biw048. 
VAN DOOREN, Thom. Wild Seed, domesticated seed: companion species and the emergence of agriculture. PAN: Philosophy, Activism, Nature, v. 9, n. 9, 20I2, p. 22-28.

VON UEXKÜLL, J. A stroll through the worlds of animals and men - a picture book of invisible worlds [s.l: s.n.]. In: SCHILLER, Claire H. (Ed.). Instinctive behavior - the development of a moderno concept. New York: International Universities Press, I964, p. 5-80. 